\title{
Um Novo Mundo, uma nova episteme: a mudança epistemológica na História Geral e Natural das Índias, de Gonzalo Fernandez de Oviedo.
}

\section{A New World, a new episteme: the epistemological change in the Natural and General History of the West Indies, by Gonzalo \\ Fernandez de Oviedo.}

\author{
Luiz Mors Cabral \\ Professor Associado do Departamento de Biologia Celular e Molecular, do Instituto de \\ Biologia da Universidade Federal Fluminense (UFF). \\ luizmors@id.uff.br \\ orcid.org/0000-0002-7478-2215
}

\begin{abstract}
Resumo. A conquista do Novo Mundo trouxe uma mudança fundamental na história do conhecimento, revelando a fragilidade de grande parte dos conhecimentos vigentes na Europa até então. Os relatos dos primeiros cronistas do descobrimento refletem métodos empíricos de sistematização do conhecimento, onde diferentes referenciais teóricos são misturados. Assim, fontes clássicas e medievais, filosofia escolástica e humanista, discursos patrióticos, religiosos e até mesmo romances de cavalaria são combinados, frequentemente de forma desarmônica, de acordo com as perspectivas ideológicas dos autores. Este artigo investiga o principal trabalho de Gonzalo Fernández de Oviedo, o livro História Geral e Natural das Índias, identificando o papel que ele teve na solução da crise epistemológica inaugurada com a descoberta do Novo Mundo, e antecipando fenômenos que mais tarde seriam motores fundamentais da revolução científica.
\end{abstract}

Palavras-chave: Revolução científica. Mudança epistemológica. Gonzalo Fernández de Oviedo.

\footnotetext{
Abstract. The conquest of the New World brought a fundamental change in the history of knowledge, revealing the fragility of much of the knowledge prevailing in Europe until then. The accounts of the early chroniclers of the discovery reflect empirical methods of systematization of knowledge, where different theoretical references are mixed. Thus, classical and medieval sources, scholastic and humanist philosophy, patriotic, religious discourses and even chivalry novels are combined, often in a disharmonious manner, according to the ideological perspectives of the authors. This article investigates the main work of Gonzalo Fernández de Oviedo, the book Natural and General History of the West Indies, identifying the role he played in the solution of the epistemological crisis inaugurated with the discovery of the New
}

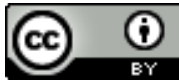


World, and anticipating phenomena that would later be fundamental drivers of the scientific revolution.

Keywords: Scientific revolution. Epistemological change. Gonzalo Fernández de Oviedo.

\section{Introdução}

Durante os primeiros anos da presença espanhola nas Américas, os espaços físicos, a flora, a fauna e os habitantes humanos das posses recém-adquiridas da Coroa precisavam ser descritos e catalogados, e seus possíveis usos avaliados. Mas exploradores, conquistadores, frades e funcionários do governo que procuraram descrever as terras desconhecidas constantemente enfrentavam a inadequação de categorias epistemológicas que haviam evoluído em um contexto europeu, e queixavam-se da incapacidade da língua de transmitir com precisão a natureza daquilo que eram testemunhas. Os primeiros relatos da natureza no Novo Mundo são um demonstrativo dessa tentativa de compreensão da nova realidade, e refletem o conflito entre as diversas tradições intelectuais e artísticas que se misturavam, muitas vezes de forma desarmoniosa, com a ciência nascente (CAÑIZARES ESQUERRA, 2006; MIGNOLO, 1995).

Embora os historiadores da ciência contemporâneos reconheçam a importância dessas obras, eles raramente se envolvem em análises textuais detalhadas, enquanto críticos literários, por outro lado, raramente se concentram em análises do discurso científico (ou protocientífico) desses relatos. Neste trabalho analisamos a principal obra de Gonzalo Fernandez de Oviedo y Valdés (1478-1557), "Historia Geral e Natural das Índias", buscando, em sua narrativa, em suas escolhas linguísticas e na maneira como Oviedo retrata o mundo natural, as contribuições para que a crise epistemológica aberta pela descoberta das Américas fosse resolvida.

\section{Gonzalo Fernández de Oviedo y Valdés}

Em seu trabalho sobre a vida de Gonzalo Fernández de Oviedo, Kathleen Myers atesta que ele nasceu em Madri, em uma família de nobres asturianos. Seu envolvimento com a Corte espanhola começou em 1478, com doze anos, quando ele se tornou camareiro de Don Juan, filho do Rei Fernando de Aragón (MYERS, 2007). Em 1493 Oviedo testemunhou, como membro da corte, o retorno triunfal de Colombo de sua primeira viagem às Américas. Com a morte súbita, em 1497, do jovem Don Juan, Oviedo passou a ocupar diversos cargos na corte, a maioria como historiador ou administrador, e em 1513 viaja às Américas para assumir o cargo de inspetor de minas e escrivão geral em Darién, onde atualmente é o Panamá (MYERS, 2007).

Gonzalo Fernández de Oviedo, sempre acreditou que a conquista dos ameríndios era mais que uma vontade da Corte Espanhola: era também seu direito e seu dever. Ele nunca 
questionou a legitimidade do papel da Espanha nas Américas e argumentava que somente a influência espanhola poderia disciplinar um povo "preguiçoso", "inclinado à mentira", e com hábitos bárbaros que incluíam "adoração a deuses pagãos" e canibalismo (Oviedo [1552], 1851, pp.109-113). Em um trecho do História Geral e Natural das Índias, ele justificou a conquista e o extermínio dos indígenas:

[...] as pessoas desta região são naturalmente tão inúteis, corruptas, de pouco trabalho, melancólicas, covardes, sujas, de má condição, mentirosas, sem constância e firmeza [...] que Nosso Senhor permitiu que fossem eliminadas e banidas da superfície terrestres (Oviedo [1552], 1851, p. 113).

\section{Descrições da Natureza}

É importante ter em mente, portanto, que Oviedo descreve a natureza do Novo Mundo como historiador da corte. De seus escritos emerge a intenção de se organizar um catálogo, com informações pertinentes, detalhadas e realistas que permitam à coroa espanhola não apenas entender a vida do Novo Mundo, mas principalmente determinar como ela poderia ser explorada. Desse aspecto emerge uma narrativa clara, diferente da grande maioria da literatura dos descobrimentos.

Uma clara vantagem de Oviedo sobre outros cronistas reside no fato dele ter adotado Plínio, O Velho, como principal referência de seu trabalho. Essa referência fica clara no número de vezes que Plínio é citado, e também na própria estrutura enciclopédica das partes de seu trabalho que tratam da natureza, catalogando plantas e espécies animais em livros de acordo com amplas categorias taxonômicas (árvores, plantas herbáceas, animais aquáticos, pássaros etc.) e dividindo os livros em capítulos sobre espécies ou grupos de espécies (PLINIO, 77).

Enquanto outros cronistas descrevem as plantas desconhecidas sempre comparando-as com os familiares já conhecidos na Europa, Oviedo percebeu que a natureza contida no novo mundo ia muito além das categorias aceitas e conhecidas, passando então a enfatizar a novidade da natureza americana. Nesse aspecto especificamente, Oviedo é, dentre a totalidade dos cronistas do novo mundo, o que vai mais longe na afirmação de que o conhecimento institucionalizado não dava conta dos novos seres, e novas categorias teriam que ser criadas. Isso fica claro quando se observa a utilização dos nomes indígenas para muitas plantas que ele descreve, não necessariamente por respeito a culturas ameríndias, mas sim como recurso para contornar a diferença insuperável entre o Novo Mundo e o Velho. Oviedo admite a incapacidade da linguagem europeia para transmitir a realidade americana.

As descrições da mandioca funcionam para exemplificar a novidade da abordagem de Oviedo. Frequentemente a mandioca era descrita fazendo-se relação de suas características com plantas já conhecidas. Tomando para fins de comparação a descrição de Bartolomé de Las Casas, outro importante cronista dos descobrimentos e contemporâneo de Oviedo, este descreve a mandioca através de uma comparação com as vinhas (LAS CASAS, 1992), representando a cultura indígena com cores baseadas na cultura européia. Já Oviedo reconhece imediatamente a singularidade da planta, e trata de dar uma descrição o mais precisa possível. Oviedo se mostra fascinado pela ideia de que a mandioca não tratada é um veneno mortal, e dedica um grande espaço de texto ao tema. Ele começa explicando nos termos mais fortes possíveis que o suco extraído da mandioca "é um veneno tão ruim que, com uma única dose pequena, ele mata o elefante ou qualquer homem"(OVIEDO, 1851). 
Para Oviedo é chocante o fato de uma cultura fazer tão largo uso de uma planta venenosa, coisa jamais vista na Europa, e é o primeiro cronista a problematizar a utilização dessa planta.

Vale ressaltar também a descrição que Oviedo faz do abacaxi, chamando atenção de sua singularidade e diferença. São quase quatro páginas inteiras com enorme riqueza de detalhes quanto a seu aspecto físico, fisiologia e propriedades como gosto e sensações que desperta e quem experimenta:

E se, por falta de cores eu não chegar à dar a entender o que pretendia dizer, que se jogue a culpa em meu juízo, pois, a meu ver, é a mais bela fruta de todas as frutas que eu já vi, e a que melhor sabor tem, e em sua grandeza e cor, que é verde, brilhante, ou matizado de uma cor amarela muito forte, e quanto mais se vai amadurecendo, mais se torna amarela e menos verde, e assim se vai aumentando a cor, e o gosto é melhor do que o gosto do mais saboroso melão, e mais suculento (Oviedo [1552], 1851, p. 302).

Oviedo, antes de mais nada, reconhece a incapacidade de descrever a fruta em comparação com qualquer outra conhecida na Europa:

Existe nessas ilhas espanholas uns cardos, que cada um deles leva uma pinha, posto que, por parecer-se com a pinha, assim as chamam os cristãos, mesmo sem o ser (Oviedo [1552], 1851, p. $302)$.

Oviedo sabe que se trata de uma planta distinta da pinha, mas reconhece que não existe nome apropriado na língua espanhola para representá-la. A descrição escrita de Oviedo contrastando a pinha e o abacaxi é bastante precisa, observando em primeiro lugar que as pinhas são "de madeira, ou quase", e depois falando que no abacaxi, ao contrário da pinha, as escamas "não se abrem nem se dividem através das escamas, como no caso dos pinhões”. (Oviedo [1552], 1851, p. 302).

Outro exemplo do cuidado de Oviedo como cronista da natureza americana vêm da forma como ele Oviedo descreve os vagalumes, incluindo alguns detalhes que outros cronistas não anotam. Ele é o primeiro a fazer uma comparação para dar uma idéia do tamanho dos vagalumes; "eles são menores que a cabeça do dedo polegar" (Oviedo [1552], 1851, p. 153). Além disso, ele estabelece uma curiosa utilidade para os vagalumes, observando que tanto espanhóis quanto índios usavam os vagalumes quando faziam guerra à noite, para não perder uns aos outros de vista, e que os guias indígenas colocavam vagalumes na cabeça para servir como farol que outros poderiam seguir. Oviedo busca também a origem da luz no vagalume, localizando-a no abdômen e anotando que eles "tem os ojos resplandecientes como velas" (Oviedo [1552], 1851, p. 153).

\section{Recursos de linguagem}

Diante da novidade da natureza americana e da dificuldade de interpretá-la sob uma ótica européia, Oviedo tenta estabelecer os princípios que deveriam nortear a exploração do Novo Mundo. Ele mesmo esclarece, em sua História Geral e Natural das Índias, que as bases epistemológicas em que funda seu trabalho como historiador natural baseia-se nos critérios de "visto pelos olhos" ou "visto e vivido" (Oviedo [1552], 1851, p. 11). Isto é, para Oviedo nada é mais válido e benéfico para um investigador do que ser "testemunha ocular", experimentando diretamente o que se investiga, seja a cosmografia, a botânica nascente, a 
zoologia ou qualquer outro campo do conhecimento científico enquadrado pela Filosofia Natural. Depois de "o que foi visto", em segundo lugar, Oviedo estabelece o critério de "o que foi ouvido"; isto é, a história que o cronista coletou de uma testemunha ocular de determinado fato natural, evento histórico ou fenômeno social. Por fim, Oviedo alude constantemente (e com alguma negatividade) a um terceiro critério proveniente da tradição escolástica, "aquilo que se lê". Assim, existe uma hierarquia na aquisição de conhecimento, onde a experiência em primeira mão ocupa lugar mais prestigioso que o conhecimento dos livros (e portanto, conhecimento dos antigos):

Mas por que eu quero trazer autoridades dos antigos nas coisas que eu vi, ou nas quais a Natureza ensina a todos e são vistas todos os dias (Oviedo [1552], 1851, p. 121).

É muito interessante acompanhar como Oviedo, que é discípulo de Plínio, e ademais era um homem muito letrado, se vê impelido a se afastar de seus mestres ao perceber as limitações do conhecimento antigo frente à novidade da natureza americana. Projetado no horizonte cultural da primeira metade do século XVI, em que o argumento da autoridade tinha a condição de dogma e o conhecimento era um exercício exclusivo de alguns círculos, essa "desobediência" de Oviedo em relação à autores antigos é um gesto revelador de uma nova e complexa atitude em relação ao conhecimento científico que está se formando no Novo Mundo.

Oviedo antecipa em seu texto uma ruptura epistemológica e a emergência do novo sujeito do conhecimento. A ruptura entre o mundo e a escrita que o continha; entre a palavra de conhecimento e a "coisa a se conhecer". Com essa ruptura, a cultura simbólica que existia até o Renascimento, e que se sustentava na coincidência entre palavra e mundo, é deixada para trás.

No seu texto, essa ruptura é caracterizada pelo uso constante da forma negativa "nem". Essa negação repetida sem pausa ao longo do História Geral e Natural das Índias, adquire dimensões dignas de menção quando Oviedo aborda, por exemplo, a questão das marés:

[...] Não é algo a ser esquecido, nem de pequena admiração, o que agora direi, que vi o mar do oceano no fluxo ou refluxo de cresce ou diminui; porque até agora nenhum cosmógrafo, nem astrólogo, nem o homem especialista nas coisas do mar, nem qualquer Natural, de muitos a quem pedi explicação, não fiquei satisfeito dada razão conveniente para a verdadeira causa que coloca em vigor o que meus olhos já viram muitas vezes e é o mistério aqui (Oviedo [1552], 1851, p. 41).

Oviedo estabelece assim um o novo sujeito do conhecimento (a testemunha ocular); uma nova base epistemológica (a própria experiência) e uma nova a categoria de verdade (a que contrasta o conhecimento estabelecido com as observações experimentadas).

Oviedo esforça-se, no História, em exemplificar para o leitor a potência dessa "nova ciência", e usa para isso um exemplo especialmente didático: a peste que havia recentemente assolado a Europa. Primeiro, há o relato da "praga":

E no ano de mil quatrocentos e noventa e seis, essa doença começou a ser sentida entre alguns cortesãos; mas nesses princípios era esse mal entre pessoas de baixa renda, e portanto, acreditava-se que eles o recebiam aproximando-se de mulheres públicas e desse 
trato libidinoso; mas depois se espalhou entre algumas das maiores e mais importantes autoridades (Oviedo [1552], 1851, p. 403).

De fato em 1496 a peste assolou quase a Europa inteira, e a medicina européia foi insuficiente para enfrentar a doença.

Foi grande admiração em todos que a viam, por ser o mal contagioso e terrível e porque muitos desses doentes estavam morrendo. E como a doença era coisa nova, nem médicos nem outros sabiam curá-la (Oviedo [1552], 1851, p. 403).

Ao revisitar esse evento, Oviedo nos lembra da capacidade limitada que o conhecimento científico europeu tradicional possui de preservar a vida, e imediatamente depois de verificar, com a morte de muitos a insuficiência da ciência médica européia, Oviedo anuncia que pode vir do Novo Mundo a cura para essa e outras moléstias: "e temos excelentes ervas, árvores e plantas apropriadas para esta e outras doenças..." (Oviedo [1552], 1851, p. 403).

A possibilidade de cura traz à tona um fato profundamente perturbador para a consciência européia pré-colombiana: que o homem europeu deve aceitar a existência de "outro conhecimento" não Europeu, não greco-latino, não católico, mas ainda assim apto a salvar sua vida.

\section{Conclusão}

As descrições da natureza de Oviedo devem ser vistas no contexto de seu papel como um funcionário dedicado do Império Espanhol. Seu livro mais importante "História Geral e Natural das Índias" foi escrito de acordo com suas responsabilidades como historiador da Coroa. Embora o livro reflita sua própria curiosidade e sua capacidade de deliciar-se com a novidade da natureza americana, ele nunca perdeu de vista seu papel como cronista real. Sendo assim, era uma de suas funções atuar na catalogação de plantas e animais para que a corte pudesse avaliar as possibilidades de exploração dos novos territórios. Imbuído dessa função primordial de catalogação, Oviedo reconhece que uma nova forma de representar a natureza encontrada no novo mundo deve ser criada, e que as categorias antigas sob as quais se organizava o conhecimento tinham que sofrer reformulações.

Logo no primeiro livro da História Geral e Natural das Índias, Oviedo declarou que a obra trataria da "cosmografia moderna das Índias Ocidentais" (Oviedo [1552], 1851, p. 7). Esse trecho, que, à primeira vista, não trazia nada de novo, pode ser interpretado como uma mudança muito significativa para o conhecimento humano, porque apresentava uma associação entre os termos "ciência moderna" e "Novo Mundo". Oviedo reconheceu que o Novo Mundo, em sua novidade, era passível de descrição. O tratamento que ele deu à natureza que observou, especialmente aquilo que não era possível de ser explicado pelo conhecimento europeu, demonstrou que Oviedo encarava a verdade científica não como aquela que se abstrai do mundo conhecido, mas sim a que se obtém na observação do desconhecido.

Oviedo vai aonde outros cronistas não conseguiram, propondo as bases de um novo conhecimento, onde a autoridade anterior possui um peso menor. Um conhecimento muito mais obediente aos critérios da experiência, de um "eu científico", ou um "eu moderno do conhecimento". Dessa forma Oviedo contribui com um primeiro passo para que a crise epistemológica aberta pela descoberta das Américas fosse resolvida. Seus relatos, tanto em 
seu conteúdo quanto na linguagem utilizada, são um divisor de águas na história das ciências naturais, iniciando o processo de descolamento de uma ciência antiga e que já não conseguia dar conta de explicar e catalogar a realidade do Novo Mundo, representando uma contribuição fundamental à revolução científica que aconteceria ao longo dos próximos séculos.

\section{Referências}

CAÑIZARES ESGUERRA, J. Nature, Empire and Nation: Explorations of the History of Science in the Iberian World. Stanford: Stanford University Press, 2006. --- Puritan Conquistadors: Iberianizing the Atlantic, 1550-1700. Stanford: Stanford University Press, 2006. Print.

LAS CASAS, B. Obras completas. Publicaciones de la Excma. Diputación Provincial de Sevilla. Editor Paulino Castañeda Delgado. Alianza Editorial, 1992.

MIGNOLO, W. The Darker Side of the Renaissance: Literacy, Territoriality and Colonization. Ann Arbor: University of Michigan Press, 1995. Print.

MYERS, K. A. Fernández de Oviedo's Chronicle of the Americas: A New History for a New World. Trans. of Oviedo, Nina M. Scott. Austin: University of Texas Press, 2007. Print.

OVIEDO, G. F. y V. Historia General y Natural de las Indias. Madrid: Imprenta de La Academia de La Historia, 1851. Disponível online em Biblioteca virtual de Polígrafoshttp://bdh-rd.bne.es/viewer.vm?pid=d-2174546, acesso em janeiro de 2020.

PLÍNIO, o V. Naturalis Historia. Universidade de Chicago. Disponível em http://penelope.uchicago.edu/Thayer/E/Roman/Texts/Pliny the Elder/home.html.

Consultado em 17 de dezembro de 2016 